\title{
ANNALS
}

$\mathrm{OF}$

\section{The Entomological Society of America}

Volume II DECEMBER, $1909 \quad$ Number 4

\section{MIMICRY IN THE BUTTERFLIES OF NORTH AMERICA.}

\author{
By Professor E. B. Poulton, Oxford, England.
}

Written from the notes of the Anniversary Address delivered to the Entomological Society of America, Baltimore, Thursday, December 31, 1908.

\section{INTRODUCTORY.}

Within a few weeks of the hundredth anniversary of Darwin's birth, and nearly midway between the fiftieth anniversaries of the publication of Natural Selection on July I last and the Origin of Species on Nov. 24 next, it seemed to me specially appropriate to select for this address a subject that is closely associated with Darwinian teachings. Although he did not publish it during his lifetime, we now know from his correspondence that Darwin independently originated the interpretation of Mimicry which was afterwards suggested by $H$. W. Bates. Its development in the mind of the naturalist of the amazons and the rival theory afterwards suggested by Fritz Müller were both of them the direct outcome, in Bates's case the very speedy outcome, of the Origin. The deep interest which Darwin took in the hypotheses of both naturalists is proved by many a letter in his published correspondence. All this forms a peculiarly fascinating chapter of ancient history,- nevertheless ancient history; but if we desire to choose a subject because of the light it can throw today and is certain to throw tomorrow upon evolution and its causes, there is no study which for promise as well as performance can be set on a higher level than Mimicry.

In the course of the following address the word "Mimicry" will be used with the restricted meaning attached to it by A. R. Wallace. It will be applied solely to the superficial resemblances between animals, and not to their likeness to vegetable or mineral surroundings for the purpose of concealment. 
The study of Mimicry is of the highest value in relation to both evolution itself and the motive causes of evolution.

Apart from all question of the means by which Mimicry has been produced, it will be generally admitted that the mimetic species has in some way evolved a superficial resemblance to the pattern of one or more species, more or less remote from it in the scale of classification. Looking on the changes by which the resemblance has been produced as a piece of evolutionary history, and, as I have said, disregarding for the moment their causes, we have one of the very simplest and sharpest pictures of organic transformation presented for our investigation. An effectgenerally a strongly marked and conspicuous effect-has been brought about in those elements which make up the superficial appearance of a species, and this important change is manifestly in the direction of only a minute fraction of the infinitely complex organic environment, viz., that fraction contributed by the superficial appearance of one or more very different species, commonly indeed of but a single one. When, as in North America, a recent invader becomes the model determining the direction of evolution in some constituent of the ancient butterfly fauna, the case becomes especially striking.

The effects produced on the mimic are generally sharper and more distinct than those seen in the concealing resemblances to bark, lichen, earth, \&c.,- the difference corresponding to the more definite and individual appearance usually presented by the pattern of the model as compared with such elements in the vegetable and mineral surroundings. There are also other important differences. The models of Mimicry are generally more restricted in their range, and differ more widely in different areas and in different parts of the same area than the models of cryptic resemblance. Differences between the local forms of the same model imply that the mimicked species has itself been subject to rapid change, while the models of cryptic resemblance appear by comparison to be stereotyped and permanent. Furthermore, the models as well as their mimics within the same area are liable to changes of distribution, whereas the models of cryptic resemblance are as a rule comparatively fixed. A mimetic species may often be found passing into an area where its model exists in a different form or does not exist at all, and highly instructive conclusions may be drawn from the study of the corresponding changes. 
In accordance with the facts briefly summarized in the above statements, we find that better and more numerous examples of rapid recent change are to be found in mimetic patterns than in those which promote concealment. Not only is this evident when we trace the geographical changes of model and mimic over a wide continuous area, but in many cases the same genus includes both mimetic and non-mimetic species, the latter enabling us to infer with more or less certainty the ancestral appearance of the former. The history thus unravelled may often be further confirmed by a study of the non-mimetic males of mimetic females.

Many naturalists at the present day incline to return to the old belief that the history of evolution has been 'discontinuous,' proceeding by "mutations" or large and definite steps of change. The comprehensive and detailed study of Mimicry as a piece of biological history certainly provides one of the best and safest means - perhaps the very best - of forming a judgment between this revived opinion and Darwin's conclusion that, although the rate of transformation varied greatly and might slow down to nothing for long periods, the steps of change were small, forming a gradual and "continuous" transition between the successive forms in the same evolutionary history.

The study of the causes of Mimicry is more difficult than that of the history of Mimicry, the conclusions far less certain. Nevertheless the evidence at present available yields much support to the theory of Natural Selection as the motive cause of evolution. The facts certainly do not point to any other interpretation. They negative the conclusion that mimetic resemblances have been produced by the direct action of external forces (Hypothesis of External Causes) or by variation unguided by selection (Hypothesis of Internal Causes). Nor do they support Fritz Müller's earlier and daring speculation that female preferences were influenced by the sight of the patterns displayed by the models (Hypothesis of Sexual Selection). The only hypotheses which are in any way consistent with the body of facts, considered as a whole, are those which assume that the resemblances in question have been built up by the selection of variations beneficial in the struggle for life.

In its concentration on a minute fraction of the total organism as well as in the rapidity of the results achieved, the operation of Natural Selection in the production of Mimicry is more than 
ordinarily akin to the methods of Artificial Selection. Indeed a very fascinating and promising line of investigation in a suitable locality would be the attempt to initiate or improve a mimetic likeness by means of Artificial Selection.

Mimetic resemblances are of two kinds, respectively interpreted by two well-known hypotheses, both based on the theory of Natural Selection.

I. Mimicry as interpreted by H. W. Bates is an advantageous deceptive resemblance borne by palatable or harmless species (the mimics) to others that are unpalatable or otherwise specially defended (the models). Such resemblance will be spoken of as Batesian Mimicry, the examples as Batesian mimics, the interpretation as the Batesian Hypothesis.

2. The resemblances between specially defended species themselves, although well known to Bates, were not explained by his hypothesis as he conceived it. He suggested that they were an expression of the common results produced by forces common to the environment of the species in question. Such likenesses ${ }^{1}$ were subsequently interpreted by Fritz Müller as the advantageous adoption of a common advertisement by specially defended species, whereby the loss of life incurred during the education of young inexperienced enemies was contributed between the similar forms, instead of by each species independently as would have been the case if they had been dissimilar, and possessed patterns requiring each a separate education. Such resemblance will be spoken of as Müllerian Mimicry, the examples as Müllerian mimics, the interpretation as the Müllerian Hypothesis.

\section{Special Advantages of the North American Butterfly Fauna for the Study of Mimicry.}

The butterfly fauna of North America affords probably the best field in which to begin the study of Mimicry, - a subject which has been shown to possess the most profound significance in relation to the deepest problems by which the naturalist is confronted. The examples are sharp and striking, but not too numerous, and the inquiry can be approached without the confusion and excessive strain on the memory which must inevitably at first beset the student of Mimicry in the tropics. But outside the tropics it is also the best field for this study, as will be shown below.

${ }^{1}$ It is probable that these were the examples which Fritz Müller had previously sought to explain by the theory of Sexual Selection. 
The western section of the Palaearctic Region is sharply cut off by the Sahara from the Ethiopian, and its few examples of Mimicry are not such as would be likely to awaken the interest and enthusiasm of the beginner. The eastern Palaearctic section suffers from the opposite defect. Separated by imperfect barriers from the Oriental Region, its butterfly fauna is complicated by much invasion of specially protected species from the tropics, and the examples of Mimicry are too numerous and too little known. North America occupies a position conveniently intermediate between the two sections of the Palaearctic portion of the circumpolar land-belt. It has been invaded by models from the eastern tropics of the Old World and also probably from the tropics of the New; but the species are few and their effects upon the indigenous butterflies sharp and distinct. The Mimicry itself affords striking and remarkable evidence of the lines of migration followed by some of the intruding models. The ancestral forms from which the mimics were derived, have nearly always persisted, and enable us to unravel the history of the change, with exceptional clearness. The examples bear in a most interesting manner upon the two great hypotheses associated respectively with the names of $\mathrm{H}$. W. Bates and Fritz Müller. Although the butterfly fauna is as well known as that of any part of the world, the mimetic resemblances supply material for a large amount of much-needed original investigation, inviting the attention of American naturalists in almost every locality.

The Danaine Models of North America, and Their Relationship to the South American and Old

World Danainae ${ }^{2}$.

The Danainae are the most important and most extensively mimicked of all specially protected butterflies in the Old World tropics. The Acraeinae, so abundant in Africa, are also greatly

${ }^{2}$ The subject of the address from this point onwards is treated in considerable detail in the author's memoir, Mimetic North American species of the Genus Limenitis (s. l.) and their models, in Trans. Ent. Soc. Lond., 1908, 447-488. Dr. Jordan's later conclusions as to the affinities of Danaida plexippus, added to the memoir in a terminal note (488) and somewhat at variance with his earlier conclusions quoted in the text, are here adopted throughout. A broader and less detailed treatment is followed in this address, special attention being directed to the numerous points on which further observations are required. Where no other authority is mentioned, I have followed the synonymy and geographical distribution of Scudder's great work, Butterflies of the Eastern United States and Canada, and, for the Papilionidae, Rothschild and Jordan's fine monograph (Nov. Zool., xiii, 1906, 411-752.) I have not, however, followed Scudder in the general use of Basilarchia as a generic name, because I think that the whole group of Limenitis, in its widest acceptation, requires revision, and that until this has been accomplished it is inexpedient to adopt the terminology proposed for a portion of it. 
mimicked, but to a far less extent than the comparatively few species of Danainae found in the same Region,- - all belonging to the section Danaini. The Ethiopian Acraeas in fact supply several mimics of the Danaines, but no example of the opposite relationship is known. In the tropical East, the Acraeinae are poorly represented, while the Danainae (Danaini, Euploeini, Hestia, Hamadryas) are dominant in numbers as well as in the power of influencing the patterns of other butterfly groups. In both Africa and the East, Müllerian Mimicry is evident between the different genera and sections of the specially protected groups themselves.

In the richest and most remarkable butterfly fauna in the world, that of South America, the dominant specially protected group is composed of the Ithomiinae, allied to the Danainae, and called by Bates "Danaoid Heliconidae." Next in importance come the Heliconinae, allied to the Acraeinae, and called by Bates "Acraeoid Heliconidae." Both of these are extensively mimicked, especially the Ithomiinae: in fact it was the close and obvious Mimicry of these by certain species of the Heliconinae that puzzled Bates and ultimately received an interpretation in the Müllerian Hypothesis. In addition to the above, this rich and varied Region contains numerous true Acraeinae, mimicked considerably, and a small number of true Danaine species. These latter, which are of extreme interest, fall into two groups. One of them, the Lycoraeini, containing the two genera Lycorea and Ituna, is confined to South America, and bears evident traces of long residence in the Region. The whole of the species are mimetic of various dominant Ithomiine genera, while at the same time some of them appear also to act as models for other butterflies, in a single case (Ituna phenarete) even for one of the rarer species (Eutresis imitatrix) belonging to the Ithominnae themselves. It was the resemblance between the Lycoraeine genus Ituna and the Ithomiine genus Thyridia that led Fritz Müller to his hypothesis, and formed the title of the paper in which he first expounded it. The Lycoraeini are widely different from any of the Old World Danainae and are sometimes separated from them as a distinct sub-family. The second group of Danaines, found in North America, as well as South, belongs to the Old World section Danaini, and is in every respect strongly contrasted with the Lycoraeini. Its species, divided into two genera Anosia and Tasitia by Moore, are not known to enter into 
mimetic relations with any of the other butterflies of this southern Region. ${ }^{3} \quad$ Furthermore, they not only belong to a dominant Old World section of the Danaines, but are even closely allied to particular species within it. It is probable that there are only two well-marked species of Danaini on the American Continent, and that the various forms encountered over this vast area are the geographical races or sub-species of these two. In north temperate America they are the well-known models for mimicry,Anosia plexippus extending far into Canada, and Tasitia berenice and its form strigosa not ranging beyond the southern States.

In 1897 , at the Detroit meeting of the American Association for the Advancement of Science, I suggested ${ }^{4}$ that the Mimicry of Anosia plexippus by Limenitis (Basilarchia) archippus was evidence that the model had long resided in North America, and that we might on this ground alone, even if we had not abundant positive evidence of its gradually increasing spread in the Old World during the past half-century, infer that Anosia had reached Fiji, Australia, Hong-Kong, \&c., in comparatively recent times. This conclusion can hardly be doubted, and the argument might have been extended to enable us to infer the ancestral line of migration by which North America itself had been reached by this form. But in r897 I followed what appeared to be the general view, that, in the New World, the original stream of Danaine invasion had run from the American tropics northward ${ }^{5}$, nor did I observe that the evidence based on the growth of mimetic resemblance warranted the interesting conclusion that its flow had taken the opposite direction, and that the south had been peopled by way of the north. Accepting this conclusion, the question arises: Whence came the Danaini of North America? The answer requires a somewhat careful comparison between the New and Old World butterflies of this group.

Among the commonest of the Old World Danaini, are certain species with tawny colouring, a black border, and black whitebarred apex to the fore wing. The under surface is even more conspicuous than the upper, being brighter in colour and the black border marked with white in a more striking manner. In one set of Oriental species, placed by Moore in his genus Salatura,

${ }^{3}$ It is possible, however, that there are incipient resemblances to Anosia in certain S. American Acraeinae.

${ }^{4}$ Proc. Am. Assoc. Adv. Sci., 1897, xlvi. 244.

${ }^{5}$ Verhandl. d. V. Internat. Zool. Congr. z. Berlin, 1901, Jena, 1902, 171. See also Essays on Evolution, (1908), 274; also errata. 
the veins are heavily marked with black on both surfaces, conferring a very characteristic appearance, especially upon the hind wing. The other set of species in which the veins are comparatively inconspicuous is placed by Moore in Limnas, including L. chrysippus, perhaps the commonest butterfly in the world, ranging from the Cape to Hong-Kong and perhaps to Japan. It is clear, however, that Africa is its ancestral home; for it is there mimicked far more extensively than in any other country. ${ }^{6}$ In the Malay Archipelago, both Salatura and Limnas are represented by various forms, and in some of these the tawny colouring becomes much darkened. This tendency appears to be more frequent in Limnas, and when both forms have darkened in the same island (e. g. Java) it is probable that Limnas has acted as the model for Salatura. There is a close general resemblance in colouring and pattern between Salatura of the Old World and Anosia of the New, as also between Limnas of the Old World and Tasitia of the New. Furthermore the two New World species differ from each other in the same points as do those of the Old. The dark, white-barred apex of the fore wing, so conspicuous in the Old World forms, is less emphasized in those of the New, being especially evanescent in Tasitia where, however, traces of the white markings remain distinct. It is significant, however, that the black and white apex is also lost in one of the forms of $L$. chrysippus, viz., the variety dorippus (= klugii) abundant in many parts of Africa and also extending by way of Aden and the west coast of India as far as Ceylon. There is, in fact, much resemblance between the pattern of dorippus and such a form of Tasitia as berenice, the likeness being especially apparent in the indications of the former presence of the white apical bar. In the forms of Tasitia, as in some of Limnas, the ground-colour becomes darker and richer--a deveiopment especially well seen in $T$. berenice of Florida. Thus the two chief points in which the pattern of Tasitia differs from that of typical L. chrysippus, viz., the darker, richer ground-colour and the evanescent apical markings, are both presented by abundant Old World forms of the latter species. The superficial resemblances between these Old and New World Danaines are precise and often extend to minute details. Thus the scent-pouch on the hind wings of the male, best seen from the under surface, is similar in Salatura and Anosia, while the resemblance between Limnas and Tasitia in this respect is even more striking.

${ }^{6}$ Proc. Am. Assoc. Adv. Sci., 1. c., 244. 
The resemblances above described suggested the investigation and comparison of structural characters in order still further to test the relationship between these Old and New World Danaines, and also the validity of the genera created by Moore. ${ }^{7}$ Such a comparison had already been partially made by Rothschild and Jordan, who in I903 published the conclusion that Limnas and Tasitia cannot be generically separated. ${ }^{8}$ I therefore wrote to my friend Dr. Jordan, asking if he would kindly extend his survey over all the four so-called genera. He found that in Salatura genutia and Anosia plexippus, having larvae with two pairs of filaments, ${ }^{9}$ the male genitalia are of the same type; while in Limnas chrysippus and Tasitia berenice, having larvae with three pairs of filaments, these genitalia are of a second type. The final opinion of this distinguished authority on the relationships between the Rhopalocera, was given in the following words: ${ }^{10}$

"It appears to be certain that Anosia plexippus does not stand apart from the others. Therefore, if Tasitia berenice, Limnas chrysippus and Salatura genutia are placed in one genus, ${ }^{11}$ plexippus also must be included. I do not think you need hesitate thus to simplify the classification of these insects."

I have no hesitation in accepting this advice, and in fusing all the four genera created by Moore into the single genus Danaida. Within this genus it has been made evident that the group of forms ranged around Danaida plexippus is the New World representative and close ally of the group of D. gemutia; while that of $D$. berenice is similarly representative of the group of $D$. chrysippus It is interesting to note that both the American Danaidas have become much larger than the corresponding Old World species,

${ }^{7}$ Proc. Zool. Soc. Lond., 1883, 201.

s Nov. Zool. vol. x, Dec., 1903, 502.

${ }^{\ominus}$ Dr. Jordan was at first inclined to think that Anosia plexippus should be separated generically, basing his conclusion in part on the larval characters (Trans. Ent. Soc. Lond., 1908, 450). A more extended review of the Tring material pointed in the opposite direction, and Dr. Jordan wrote on December 10, 1908, as follows:- 'I find from our specimens (of preserved larvae) that-

(1) in Euploea (in the wide sense) there are 4 pairs of filaments, or three (the 3rd being absent), or two (the 3rd and 4 th being absent).

(2) In Danaidae, incl. of Anosia \& Limnas, there are 3 pairs (the $3 \mathrm{rd}$ of the 4 pairs of Euploea being absent), or 2 pairs (the 2 nd and 3rd being absent). I find that, for instance, genutia and purpurata have 2 pairs only, like plexippus. The larva therefore does not furnish any argument for separating plexippus as a genus.'

${ }^{10}$ In a letter to the author, dated December $15,1908$.

${ }^{11}$ Dr. Jordan's opinion that these three genera should be united is quoted in Trans. Ent. Soc. Lond., 1908, 450. 
and that the most northern forms are larger than the southern in both hemispheres - the probable result of a slower metamorphosis in a more temperate climate.

Evidence That Danaida Is An Old World Genus That Has INVADED THE NEW.

The suggestion might perhaps be made that the New World forms of Danaida are the more ancestral, and that those of the Old World have been derived from them by migration westward. There is no reason for concluding that the Danaidas of either geographical area possess a more primitive structure than those of the other; we are therefore driven to consult other lines of evidence. The following comparisons clearly indicate that Danaida is an Old World genus which has invaded America at no very remote period: (I) the far larger number of the Old World forms and the greater degree of specialization by which some of them are distinguished; (2) the place of Danaida as one out of a number of nearly related genera making up the Danaini, a large and dominant Old World group, per contra its isolated position in the New World; (3) The highly developed and complex mimetic relationships of the Old World Danaidas.

This last statement requires some expansion and exemplification. Allusion has already been made to the resemblances which have grown up between different species of Danaida in the same island,-resemblances in which the forms of chrysippus appear to act as models. Even more striking is the mimetic approach of certain Old World Danaidas to species of the other dominant Oriental section of the Danainae-the Euploeini. Thus in the Solomons, Danaida (Salatura) insolata is a beautiful mimic of the dark-white-margined Euploea brenchleyi, while in the same islands Danaida (Salatura) decipiens mimics the dark, white-spotted Euploea asyllus. ${ }^{12}$ Finally, and most convincing as evidence of long residence, are the numbers of mimics which in the Old World have taken on the superficial appearance of species of Danaida. In addition to the extraordinary degree to which the Mimicry of $D$. chrysippus is carried in Africa, it is mimicked in the Oriental Region by the females of Hypolimnas misippus and of Argynnis niphe, and by the males of certain species of Cethosia. Danaida genutia and the forms related to it are also

${ }^{12}$ See J. C. Moulton in Trans. Ent. Soc. Lond., 1908, 603, 604: P1. XXXIV, figs. 5,10 . 
mimicked by male Cethosias and extensively by the females of species of Elymniinae, while incipient Mimicry is seen in the males of some of them. With the exception of Hypolimnas misippus, common to both Regions, the Oriental mimics of Danaida do not approach the degree of resemblance attained by the best African mimics of $D$. chrysippus. It has already been pointed out that the Oriental mimics of this genus are far less numerous than the African. On the other hand, it is a curious fact that the only North American mimic of D. plexippus,-Limenitis (Basilarchia) archippus - reaches a far higher degree of resemblance than that attained by any of the characteristically Oriental mimics of Danaida.

The evidence as a whole enables us to decide that Danaida is an Old World genus and a compraatively recent intruder into America, while the perfection of the likeness attained by an indigenous American mimic proves that, under favourable circumstances, such resemblances may be rapidly produced. I do not, of course, mean to imply that the transformation was in any way sudden, or by other than minute transitional steps. The evidence for this conclusion will be clearer when some of these steps have been described in detail. (See pp. 214-I7.).

\section{The Line of Migration by Which Danaida Originally Entered America.}

There can be little doubt that $D$. plexippus invaded America by way of the north, probably following the line of the Aleutian Islands. In North America it possesses an astonishing distribution for a member of so tropical a group ranging immensely further north than any other Danaine in the world. Furthermore, D. genutia, the probable representative of its Old World ancestor, extends far beyond the tropics into Western and Central China. A study of the distribution of the Asclepiad food-plants on the eastern coast of Asia might perhaps throw light on the problem. D. plexippus was certainly the earlier of the two invaders of the New World. This is clearly shown by the extent of its own modification no less than by the changes it has itself produced. Its immense size, the shape of the hind-wing cell, and the form of the fore wings indicate that it is far more widely separated than is $D$. berenice from the nearest Old World species. It has furthermore been resident in North America long enough to effect profound changes in the pattern of an indigenous Nym- 
phaline butterfly, rendering it an admirable mimic; whereas $D$. berenice, and probably its form strigosa also, have only effected comparatively slight modifications in the mimetic pattern already produced under the influence of plexippus (see pp. 2 I 7 -I8). It is impossible to feel equal confidence in suggesting the line by which the later invasion of the more tropical $D$. berenice took place; but it is on the whole probable that it too came by way of the north during some temporary period of warmth. It is tolerably certain that it did not invade North America from the south. For although $D$. berenice and strigosa have produced - as is shown above - far less change in the indigenous N. American fauna than plexippus they have still caused distinct and perfectly effective modifications in a single species; whereas in South America their representatives have not been shown to have had any effect at all. It is probable that both the American Danaidas as they pressed southward were "held up" for a considerable time at the northern borders of the Neotropical Region, unable at first to penetrate that crowded area. Finally they burst their way through and are now abundant throughout all the warmer parts of the Region, the forms of plexippus extending further into the temperate south, just as in the Northern Hemisphere they range further north than those of berenice. We are made to realize the recent date of the invasion of South America when we remember that nowhere else in the world do Danaine butterflies of equal abundance "range through a crowded area without producing any effect on any member of the Lepidopterous fauna, or without themselves being affected thereby." ${ }_{13}$ Abundant wide-ranging Danaines in the Old World, even when much smaller and with a less marked appearance, invariably produce some effect, and often themselves exhibit Müllerian resemblances.

\section{The Evolution of Limenitis (Basilarchia) archippus as a Mimic of the Invading Danaida plexippus.}

It has already been mentioned that a single species, undergoing corresponding modifications, provides a mimic for each of the three Danaine models (including strigosa). We will first consider the well-known beautiful mimic of $D$. plexippus; for it undoubtedly arose earlier than the others.

The abundant Limenitis or Basilarchia archippus is closely related to the Palaearctic species of Limenitis, a group which

${ }^{13}$ Trans. Ent. Soc. Lond., (1908), 452. 
includes the well-known British "White Admiral" (L. sybilla). The example is unusually instructive, because the non-mimetic ancestor of the mimic is still very abundant in Canada and the north-eastern States, and we thus possess the material for reconstructing the history by which the one form originated from the other. We know that this ancestor, Limenitis arthemis, has persisted almost unchanged, because of the resemblance between its pattern and that of the other species of Limenitis (using the name in the broad sense) from all parts of the circumpolar land-belt, including North America itself. The difference between the pattern of the mimic and that of its non-mimetic parent is enormous - probably as great as that between any two butterflies in the world; but the steps by which the transition was effected were long ago suggested by S. H. Scudder, ${ }^{14}$, and have recently been worked out in considerable detail by the present writer. ${ }^{15}$

$L$. arthemis exhibits the characteristic "White Admiral" pattern-possessing on the upper surface a dark ground-colour with a broad white band crossing both wings, and white markings within the apex of the fore wing. Reddish or orange spots between the white bands and the margin are found in the hind wings of many individuals, more rarely in the fore wings. These latter markings are of the utmost importance, for, as Scudder long ago pointed out (1. c., 7 I 4), they undoubtedly provided the foundation for the change into the mimetic archippus.

A careful comparison between arthemis and archippus reveals the most conclusive evidence of selection. The one species has become changed into the other precisely as if an artist were to paint the pattern of archippus upon the wings of arthemis, retaining unchanged every minute part of the old markings that could be worked into the new, and obliterating all the rest. Thus, extending in this direction and wiping out in that, the great transformation has been effected and one of the most beautiful mimics in the world produced.

The evolution of the mimetic pattern on the under surface has involved an even more elaborate change than on the upper; but it is not necessary to repeat here the details which have been only recently fully described. ${ }^{16} \quad$ I will, however, allude to the fate of

${ }^{14}$ Butterflies of the Eastern United States and Canada, Cambridge, Mass. (1889), 278, 714 .

${ }^{15}$ Trans. Ent. Soc. L'ond., (1908), 454-460.

${ }^{16}$ Trans. Ent. Soc. Lond. (1908), 454-460). 
the most conspicuous feature of arthemis, the broad white band crossing both wings. Save for the traces mentioned below, this marking has disappeared from both surfaces of the hind wing of archippus, but its black outer border is retained, and, cutting across the radiate pattern formed by the strongly blackened veins, detracts considerably from the mimetic resemblance. ${ }^{17}$ On the under surface distinct traces of the white band may commonly be seen along the inner edge of the persistent black border. So far as my experience goes, these traces are only to be found on the upper surface in the form hulsti (Edw.). The modification of the same marking in the fore wing is more interesting. Here towards the costal margin the black outer border is much expanded, invading the white band and cutting off from two to four white spots from its outer part. While the rest of the band disappears except on the costa itself, these black-surrounded white spots now represent the sub-apical pale-spotted black bar of the model. The new marking is larger and more conspicuous on the under surface, corresponding with the strong development of white on this surface of the model. The costal margin of the fore wing of the latter is streaked with long narrow white markings. In correspondence with this we find, commonly on the under surface, more rarely on the upper, that the extreme costal end of the white band is retained, often for the full breadth of the marking, forming a linear streak.

${ }^{17}$ 'In the course of the address on December 31, 1908, I remarked that if we could revisit the earth in a few hundred years, we might expect to find that this black line had disappeared from the hind wing, and the mimetic resemblance correspondingly heightened. At the conclusion, Mr. John H. Cook, of Albany, $\mathrm{N}$. $\mathrm{Y}^{\mathrm{r}}$, informed me that he had discovered near his home many indviudals in which the black line was wanting from the upper surface. A few days later he very kindly sent me a record of his observations, of which an abstract is printed as a note at the end of this address (see pp. 241-42). The study of Mr. Cook's facts shows that near the city of Albany not only did the stripeless variety occur commonly ( 1 in 14), during the three seasons in which the observations were conducted, but also transitional forms with more or less broken stripes were far commoner than the normal archippus (18 to 1 ). The fact that entirely stripeless individuals were invariably males is contrary to the rule that mimetic resemblance tends to develop more rapidly and fully in the other sex. But in this species I have observed another point in which the female tends to be more ancestral than the male, viz., the more frequent and complete development of the white spot in the cell of the fore-wing upper surface (a common feature of Limenitis, although now generally absent from $L$. arthemis).

Mr. Cook's observations show that a single marking - and one so simple that we might have expected it to act as a unit, so small a traction of the pattern that we could hardly speak of its sudden disappearance as an example of "discontinuous" evolution - that even this behaves differently on the two surfaces of the wing, while the individuals from which it has disappeared are immensely outnumbered by those in which it is transitional. 
I have dwelt upon the changes undergone by the white band as an example of the way in which the new markings have been carved out of the old. The changes in the elaborate marginal pattern would have been equally convincing as evidence for a gradual and "continuous" transformation.

The Modification of the Limenitis Mimic of Danaida plexippus into a Mimic of D. Berenice in Florida.

Danaida plexippus occurs together with $D$. berenice in Florida, but the latter far outnumbers the former, and the modification of Limenitis archippus into the form floridensis, Strecker (=eros, $\mathrm{Edw}$.) is probably entirely due to the predominance of one model over the other. Data for determining the exact proportions in various localities would be of high interest. There is no reason for believing that berenice is in any way more or less distasteful than plexippus, but its abundance makes it a more conspicuous feature in the environment.

It is evident that the change has been of the kind expressed in the above heading; for, as has been already implied in pp. 2 I 3 -I 4 , traces of the former Mimicry of plexippus persist in floridensis and tend to detract from the resemblance more recently developed. This is especially the case with the conspicuously blackened veins of archippus, which are so important a feature in the likeness to plexippris. These, although obscured by the general darkening, are still recognizable in floridensis, diminishing its resemblance to berenice on the upper surface of both wings and on the under surface of the fore wing. Inasmuch as the details have been recently published elsewhere, ${ }^{18} \mathrm{I}$ will only dwell on one further point in the resemblance of floridensis to berenice - and that because the extensive observation of large numbers of specimens is greatly needed. I spoke on pp. 2 I 5-I 6 of the persistent traces of the white band on the hind-wing under surface in many individuals of $L$. archippus. These are ancestral features, diminishing the mimetic resemblance to $D$. plexippus. But in $D$. berenice there are conspicuous white spots towards the centre of the hindwing under surface, and these, at any rate upon the wing, would bear some resemblance to the ancestral spots of the Limenitis mimic. Now in my very limited experience of floridensis these spots were sometimes exceptionally developed and, outlined with black on their inner edges, were certainly far more distinct and

${ }_{18}$ Trans. Ent. Soc. Lond. (1908), 460, 461. See also Scudder, 1. c. 718. 
conspicuous than in L. archippus. The appearances I witnessed suggested the possibility of the recall of a vanishing feature in consequence of selection based on a likeness to certain white spots present in the new model (berenice) but absent from the old (plexippus). But many hundreds of specimens from different localities scattered over the total area of distribution require to be examined from this point of view. An even more interesting inquiry would be to trace the range of the floridensis form northward and determine the relationship of its limits to the zone in which berenice becomes scarce and disappears, and above all to ascertain whether floridensis on the borders of its range interbreeds with archippus and how far transitional varieties occur. Interbreeding between the two forms, if possible, would be of extraordinary interest. It is also of importance to ascertain precisely how far the one form penetrates the area of the other. Scudder indeed states that floridensis ranges into the Mississippi Valley and Dakota, far beyond the limits of Danaida berenice. It would be deeply interesting to make an exact comparison between such specimens and those from Florida, and also to ascertain the proportion which they bear to typical archippus. By far the most important feature in the evolution of floridensis is the general darkening of the ground-colour, and the material for such a transformation certainly exists freely in archippus, for the shade of brown varies immensely and may often be seen of as dark a tint as in floridensis, but not in my experience of precisely the same shade. The proportion of such dark forms in various parts of the immense range of archippus would be another interesting inquiry.

\section{The Modification of the Limenitis Mimic of Danaida} PLEXIPPUS INTO A Mimic OF THE STRIgOSA FORM OF D. Berenice in Arizona.

The differences between $L$. archippus and the form hulsti (Edw.) are more striking than those which distinguish floridensis from the former. The upper surface of the hind wing of hulsti retains or more probably has recalled distinct traces of the white band, although the black stripe is evanescent. It is probable that upon the wing, these vestigial white markings produce a general likeness to the pale-streaked hind-wing upper surface of strigosa. Other points in which hulsti differs from archippus and approaches strigosa are the reduction of black and the general appearance of 
the white spots in the subapical region of the fore wing, and the dull tint of the ground-colour. I have had hardly any experience of this interesting form and owe the above details to Dr. W. J. Holland's figure and description. ${ }^{19}$ It is obvious that all the investigations suggested in the case of floridensis are, mutatis mutandis, equally available and equally important in the form hulsti.

The geographical distribution of hulsti strongly supports the conclusion that it was derived from archippus and not immediately from an arthemis-like ancestor. I have not yet had the opportunity of ascertaining whether this hypothesis is supported by evidence derived from a careful study of the pattern.

It is deeply interesting to observe that the same Limenitis arthemis-like species, from which archippus, floridensis, and hulsti-mimics respectively of the three Danaidas, plexippus, berenice and strigosa - have been directly or indirectly evolved, has also given rise to L. astyanax (ursula), the mimic of a Papilionine model. Evidence in favour of the comparatively recent origin of these mimicking forms is to be found in the well-supported facts which indicate that astyanax still interbreeds with arthemis along their geographical overlap, and that it may even occasionally pair with the sister species archippus. ${ }^{20}$

The earlier stages of archippus and astyanax are, according to Scudder (1. c. 254,255 ), with difficulty distinguished from those of arthemis, but astyanax presents the closer likeness of the two; a fact which, together with those referred to in the last paragraph, points to the conclusion that it arose even more recently than archippus,

The further consideration of astyanax is best deferred until some account has been given of the Papilionine models, and until certain general conclusions have been discussed in the following section.

Bearing upon Theories of Mimicry of the Transformation Wrought by the Invading Danaidas.

It has been shown that the Danaine models invaded America from the Old World tropics, probably following a northward route. Their patterns are but little changed in the new surroundings, and they still keep the characteristic appearance of Old World

${ }^{19}$ Butterfly Book, 84, 185, P1. vii. f. 5. Dr. Holland fully recognizes the mimetic significance of the pattern and colouring of hulsti.

${ }^{20}$ Scudder, 1. c. 283, 289. Trans. Ent. Soc. Lond. (1908), 473, 474. 
Danaidas. Furthermore, such changes as have taken place in the older invader, $D$. plexippus, during its residence in the New World, are also retained in those colonies which, during the half century, have been re-establishing themselves in the Old World. These facts support Darwin's conclusion that the physicochemical influences of soil, climate, etc., are of comparatively slight importance, a conclusion which made him feel "inclined to swear at the North Pole, and $* * *$ to speak disrespectfully of the Equator.', 21

The mimics on the other hand are derived from characteristic and ancient inhabitants of the northern land-belt. If, as the followers of the theory of External Causes (see p. 205) maintain, species are the expression of the physical and chemical forces of the environment, then the Danaidas express the Old World tropics and the species of Limenitis the northern land-belt. We might expect on this theory that the Danaidas, when they invaded the northern zone, might come to resemble the Limenitis; but the transformation that has actually occurred is entirely inconsistent with any such hypothesis. Although the Danaidas have undergone no important change in the new environment, their presence has entirely transformed and brought into a close superficial resemblance to themselves the descendants of a member of an ancient group. Such a fact is inconsistent with any interpretation as yet offered except that which refers the change to the accumulation by selection of variations which promote a likeness to the Danaidas.

The facts also bear upon the two theories of Mimicry associated with the names of $\mathrm{H}$. W. Bates and Fritz Müller. According to Bates' theory, Mimicry is a special form of protective or cryptic resemblance. In the ordinary examples of this principle, species are aided in the struggle by concealment, by a likeness to some objects of no interest to their enemies (such as bark, earth, etc.); in these special examples (called mimetic) species are aided by resembling some object which is unpleasant or even dangerous to their foes. Fritz Müller's theory of Mimicry includes the cases in which the mimics, as well as their models, are specially defended, although generally to an unequal degree. The $\mathrm{T}^{22}$ resemblance is due to the advantages of a common advertise-

${ }^{21}$ In a letter to Sir Charles Lyell, Oct. 11, 1859.-Life and Letters, ii. 212.

${ }^{22} \mathrm{It}$ is probable that relative abundance may determine the relationship of model and mimic in cases where there is no reason for suspecting any difference in the degree of unpalatability. 
ment. Before the growth of a mimetic likeness, Batesian mimics, it is reasonable to assume, belonged to the immense group of species possessing a cryptic appearance; Müllerian mimics on the other hand may be assumed to have possessed warning or aposematic colours of their own previous to the adoption of those of another species. This test is more readily applied than might be supposed; for a comparison with allied non-mimetic species, and with the non-mimetic males of mimetic females, will generally indicate whether the ancestral pattern of a species now mimetic belonged to the group of concealing colours or to that of warning.

The Danaidas invaded North America and entered an assemblage of butterflies of which the dominant species are ancient inhabitants of the northern land-belt. Among them are several such as the species of Grapta or Polygonia (the "Comma" butterflies), with beautifully cryptic patterns on the parts of the wing surface exposed in the resting position. No such forms have been influenced by the invaders, but with the whole fauna before them they have only produced changes in the dominant group Limenitis, known throughout the northern belt for a conspicuous under surface and a floating flight; also believed to be mimicked by other butterflies, e. g., the females of the Apaturas ("Purple Emperors") and the later brood of Araschnia levana. ${ }^{23}$ Furthermore, the close allies of Limenitis in South America, the abundant Adelphas, are beautifully mimicked, not only by females of the genus Chlorippe, which represents Apatura, but also by Erycinidae. In another point the facts are at variance with Bates' interpretation but harmonize with Müller's. Bates supposed Mimicry to be an adaptation by which a scarce, hardpressed form is enabled to hold its own in the struggle for existence But L. arthemis, which represents with little or no change the species from which the mimics were derived, persists as a very abundant and flourishing species, while its mimetic descendant archippus has gained an immensely extended range and become almost universally commoner than any other species of its group (Scudder, 1. c. 266). L. archippus extends from Hudson's Bay to the Gulf of Mexico; over this vast area it is only rare in the west, and only unknown in Colorado, Arizona, and New Mexico (1. c. 278). It is to be observed that the range of archippus includes the whole of the area (Canada and the north-eastern States) occupied by the ancestral form arthemis.

${ }^{23}$ See also the mimetic resemblance to L. astyanax described on pp. 229-30. 
The facts indicate that the changes produced by the invaders were wrought in the conspicuous pattern of a dominant indigenous species, and that the transformed butterfly having adopted the advertisement of the still more unpalatable Danaida, became even more dominant and gained a far wider range than before. The mimetic resemblance arose in a species which we have reason to believe possessed warning colours and some form of special protection before the change occurred. There is no evidence that the special protection was diminished after the assumption of Mimicry, and, if it remain, the new appearance is still a warning character, only one that is learnt by enemies more readily than the old because of the wide advertisement given to it by Danaida plexippus. The facts harmonize with the theory of Fritz Müller rather than with that of $H$. W. Bates.

The 'Poison-Eating' Swallow-Tail Butterflies (Pharmacophagus) as Models for Mimicry.

The late Erich Haase gave the name of Pharmacophagus or "Poison-eater" to the section of swallow-tail butterflies whose larvae feed upon Aristolochia or allied species, and he made the probable suggestion that the qualities which render them distasteful are derived from the juices of the food-plant. The poison-eating swallow-tails are abundant in tropical America and the Oriental Region, but with the exception of antenor in Madagascar are wanting from the Ethiopian Region. They are extensively mimicked by swallow-tails of the other two sections: Papilio, of which machaon may be taken as a type, and Cosmodesmus, of which podalirius serves as an example. The distinction between these three sections of Papilionidae extends to larval and pupal stages, as was originally discovered by Horsfield. It was made the basis of Haase's classification, ${ }^{24}$ recently confirmed and amplified by Rothschild and Jordan. ${ }^{25}$ The latter authorities propose the names "Aristolochia Swallow-tails," "Fluted Swallow-tails," and "Kite Swallow-tails," respectively for Haase's sections Pharmacophagus, Papilio and Cosmodesmus.

The Pharmacophagus swallow-tails are not so well-known as models for Mimicry as are the Danainae, Acraeinae, etc., and it is therefore expedient to say a few words about the section before considering the effect produced by one of its members in North America.

${ }^{24}$ Researches on Mimicry, Pt. ii, Stuttgart, 1896, English translation.

${ }^{25}$ Nov. Zool. xiii (1906), 411-752. 
In tropical America not only are the species of Pharmacophagus extensively mimicked but Mimicry is also strongly developed within the limits of the section itself, viz., between the two dominant groups Aeneas and Lysander. In these groups the males are commonly very different in appearance from the females and frequent more open habitats such as the banks of rivers, etc., the females being found in the forest. In the internal Mimicry between Aeneas and Lysander the males resemble the males, the females the females, but the female patterns are alone extensively mimicked by other groups-Papilio, Cosmodesmus and certain Pierinae. I have as yet only come across a single example (a Cosmodesmus) in which the pattern and green markings of the males are mimicked. One or two species (e. g. Ph. hahneli) of Pharmacoghagus are themselves mimics of dominant Ithomiine genera.

It is well known that in the Papilio mimics of Pharmacophagus the resemblance is often attained by the females alone, a tendency exemplified in North America as shown on pp. 224-6. In Cosmodesmus, on the other hand, where the Mimicry of these models reaches a far higher level of perfection, it is equally pronounced in both sexes. In Africa, on the other hand, where, in default of Pharmacophagus models, the swallow-tails of both groups frequently mimic Danainae and Acraeinae, the resemblances obtained by Cosmodesmus are far less striking than those of the other section; yet the relationship of Mimicry to sex remains unchanged.

In the Oriental Region the female Mimicry of Pharmacophagus is still characteristic of Papilio, also appearing in certain Cosmodesmus mimics of Danainae. Two remarkable features appear in this Region: (I) the development within Pharmacophagus of the gigantic Ornithopteras which do not appear to be mimicked at all; (2) the appearance within the section Papilio of groups which are mimicked as extensively, perhaps even more extensively, than Pharmacophagus itself. Among the mimics of these Papilios are not only species of other proups in the same section but also, although in small proportion, Satyrine butterflies and day-flying moths.

The fact that Pharmacophagus and certain groups of Papilio should be mimicked pre-eminently by other Papilionidae is evidence that Mimicry is most easily attained when there are initial resemblances of size, shape, habits, and modes of flight upon which to build. 


\section{Pharmacophagus (Papilio) Philenor L., as a Model for Mimicry in North America.}

Pharmacophagus is a tropical assemblage, but a few species have found their way into the northern belt in both the old World and the New. Pharm. polydamas, with an immense range in South and Central America, also extends into the northern continent but does not there become the object of Mimicry. Pharm. philenor, ranging through Mexico and the United States (except the central district from Colorado northwards) but only as a straggler in New England and southern Canada, is on the other hand an important model for Mimicry.

There is here no such interesting history of past migrations to unfold as we were able to trace in the American Danaidas. Ph. philenor is a member of the distinctively New World species of Pharmacophagus associated together and separated from the Old World species by structural characters. Rothschild and Jordan state that every species can be recognized as American by the examination of a single joint of one leg, and they are therefore justified in concluding that all the New World species were derived from a single ancestor possessing this character. There is no sufficient evidence that any of the numerous patterns are ancestral as compared with the others, although it is tolerably safe to conclude that the presence of hind-wing "tails" is primitive as compared with their absence. Following this indication, we find that as a general rule the specialized and modern forms are predominant nearer to the Equator, the comparatively ancestral tailed forms occurring in latitudes more remote from it both north and south.

Ph. philenor is a "tailed" form, although its sub-species orsua in the Tres Marias Islands is nearly tailless. It is probably an intruder into North America from the tropics of the same Continent. It is well known to possess the characteristics of distasteful species - gregarious larvae, tenacity of life, and a strong, disagreeable scent.

The Three Papilio Mimics of Ph. Philenor in North America.

The three swallow-tail mimics of philenor belong to separate groups of Haase's section Papilio. All of them range from the Atlantic to the Mississippi basin. 
The female of Papilio polyxenes asterius (Cr.) belonging to the Machaon Group mimics philenor on both surfaces, the male on the under surface alone, except at Guerrero, Mexico, where a form (ampliata) mimetic on the upper surface is transitional into the ordinary male.

Papilio glancus glancus (L.) belongs to the Glaucus Group, next but one to the group containing asterius. ${ }^{26}$ The female is dimorphic, one form resembling the male and the other, the turnus form, mimetic of philenor (L.), becoming commoner in the southern part of the range. In the closely allied sub-species $P$. glaucus canadensis (Rothsch. and Jord.), the mimetic female form is unknown.

Papilio troilus troilus (L.) belongs to the next succeeding Troilus Group, allied to the tropical and highly mimetic Anchisiades Group, with gregarious larvae. Both male and female of troilus mimic philenor on both wing surfaces.

The most remarkable fact about these three mimics is not their moderate resemblance to the primary model philenor, but their extraordinary likeness to one another. Upon the wing or at rest at a little distance they would be indistinguishable, and even in the cabinet they may be easily confused. It is to be expected that the species of allied groups, with patterns converging towards that of a single model, and approaching it by variations which tend to be produced in the section to which they belong, should incidentally approach one another. But the strong likeness between the mimetic forms of troilus asterius, and glaucus seems to require something more than this, and supports the conclusion that there is secondary Mimicry between the mimics themselves. It is not necessary to repeat here the details of these secondary resemblances, ${ }^{27}$ and as a matter of fact the likeness itself is stronger than might be inferred from a consideration of the details themselves. It is necessary to see it in order to appreciate it.

It is probable that troilus, mimetic in both sexes, is the oldest mimic; asterius, non-mimetic on the upper surface of the male or with very rough incipient Mimicry, the next to appear; and glaucus, mimetic in only one form of the female, the youngest. These conclusions as to relative age are on the whole supported by the relative strength of the detailed resemblances to philenor in the three mimics.

${ }^{26}$ The species is commonly called $P$. turnus and its mimetic female the glaucus form. I follow Rothschild and Jordan in transposing these names.

${ }^{27}$ See Trans. Ent. Soc. Lond. (1908), 467-471. 
In attempting to trace the past history, here again we have the great advantage of knowing the more ancestral patterns from which the three mimics were derived:- troilus from a palamedes-like form; asterius from the pattern of its male, which again leads back to the typical pattern of the Machaon Group: the turnus female of glaucus from the male and non-mimetic female of the same species.

It is highly probable that the earliest steps in the direction of Mimicry in asterius and glancus were favoured by the appearance of partially melanic varieties of the female, thus effecting suddenly that essential change which enables a butterfly with a yellow ground-colour to become the mimic of one in which it is black. But this transformation, immensely important as it is, supplies nothing more than a tinted paper for a new picture. That the melanic varieties were partial is clearly shown by the persistence (in glancus) in a subdued and inconspicuous form of certain ancestral features that do not contribute to the Mimicry, but above all by the retention of every element in the original pattern that can be worked up into the new. By the modification of these elements in form or colour,- often in both form and colour,- the detailed mimetic pattern has been wrought upon the darkened surface.

Valuable confirmation of the history suggested in the last paragraph is to be found in the dark form melasina (Rothsch. and Jord.) found in both sexes of $P$. polyxenes americus (Kollar), extending from North Peru to Colombia and Venezuela. This melanic variety probably represents the darkened form of asterius before the initiation of the detailed mimicry of philenor. The sub-species americus does not enter the range of philenor, and those ancestral elements which have been retained by its melanic form have not developed into the mimetic likeness seen in the more northern sub-species asterius.

It is well known that all four species (including philenor) fly together. Even in my own limited experience I have taken three of them in adjacent streets on the outskirts of Chicago on the same day (Aug. Iо, I897), and the fourth in the same locality a little earlier (July 28). But precise knowledge of their relative proportions in different parts of their range would be of highest interest. Again, troilus extends to the North-West Territory of Canada, probably far beyond the area in which philenor occurs as a straggler; and it would be very interesting to compare min- 
utely large numbers of such specimens with those from districts where the model is dominant. A similar study should be made of the Canadian specimens of asterius, although this species does not extend so far beyond the northern limits of the poison-eating model.

From another point of view the interbreeding of the turnus female of glaucus with a male from some northern district where turnus is unknown or very scarce would be of the highest interest. We should here be able to test whether the Mendelian relationship exists between the parent form and its partially melanic variety further transformed by selection, - not a mere melanic "mutation." I trust that my friend Prof. C. B. Davenport may be able to undertake this experiment at the Cold Spring Experimental Station. I cannot doubt that breeding could be easily carried through two generations in a large enclosed space exposed to the sun and planted with abundant flowers and the food-plant of the species. It would probably be safe to use Long Island males, while female pupae or the freshly bred females themselves could be readily obtained from further south.

The Evolution of Limenitis (B.) astyanax (F). as a Mimic of Ph. philenor and Its Papilio Mimics.

Scudder states that L. astyanax "ranges from the Atlantic westward to the Mississippi Valley, and from the Gulf of Mexico northward to about the 43 rd parallel of latitude." ${ }^{28}$ It thus falls entirely within the area of philenor. The northern boundary of astyanax corresponds with the southern limit of its parent arthemis, and Scudder (1. c. 289) considers that they interbreed and that the intermediate form proserpina, found along the narrow belt where the two species or sub-species meet, is the resulting hybrid. Both arthemis and proserpina have been bred from the eggs of the latter. There seems little doubt that astyanax is a very recent development from arthemis in the southern part of its range,- - so recent that the areas of distribution still remain distinct and parent and offspring only meet along a narrow line. It is probable that archippus arose in the same manner in part of the area of arthemis, but that later, after the separation had become complete, it spread northward over the whole range of its parent.

${ }^{28} \mathrm{~A}$ closely allied species or probably a form of the same species is recorded by Godman and Salvin from Mexico. 
The evolution of astyanax from arthemis was far simpler than that of archippus. The great difference in appearance between parent and offspring is brought about, as regards the upper surface, by the disappearance of the broad white band of arthemis together with all but a trace of the sub-apical white markings of the fore wings. Over and within the area formerly occupied by the white band, a bluish or greenish iridescence spreads from the marginal region where it exists in arthemis. This marginal iridescence - just as in astyanax - is bluish in some individuals of arthemis, greenish in others. Reddish sub-marginal spots, although rarer in the hind wing of astyanax, are actually commoner in the fore wings than in arthemis. This curious fact, together with the evidence that astyanax and archippus may occasionally interbreed, suggests the possibility of some connection between the origins of the two mimics.

The under surface of astyanax has not only similarly lost the white markings, but the chocolate-brown ground-colour of arthemis has become transformed into a iark iridescent greenishbrown. Against this background the reddish spots near the margin and base of the wings become far more conspicuous than in the parent form. The material for this transformation in tint is still to be seen in the great variation of the ground-colour in arthemis.

Although, as Scudder rightly maintains (1. c. 287 ), L. astyanax is a very poor mimic of Pharm. philenor, it bears considerable resemblance to the three Papilio mimics, especially troilus. Although the iridescent blue or green of its upper surface approaches rather more closely than the Papilios to the brilliant, steely lustre of philenor, it is still in this respect widely separated from the primary model and near to the mimics. The reddish spots of the under surface offer but a rough likeness to those of any of the above named species, but there can be no doubt that their emphasis is an element in the mimetic resemblance.

A careful examination of large numbers of astyanax from the extreme south of the range where it passes out of the area of glaucus and troilus but remains within that of philenor and asterins, might yield interesting results. An investigation of the proportion it bears to the four Papilionidae in various parts of their common range would also be of deep interest. Of the highest importance would be the attempt - which would probably be successful - to breed astyanax and arthemis and to ascertain 
whether the Mendelian proportions appear in the offspring of the hybrids. The pairing of astyanax and archippus, although in this case failure is probable, ought also to be attempted.

\section{The Female of Argynnis (Semnopsyche) diana (Cr.) a Mimic of Limenitis astyanax.}

The comparatively narrow range of this species is, as Scudder points out, wholly included within that of astyanax (1. c. I802). The Mimicry is confined to the upper surface, where the blue tint has even less sheen than that of any other member of the group clustered round the brilliant philenor. Apart from the blue expanse, which he admits to be mimetic, Dr. F. A. Dixey considers that the female of diana belongs to a set of dark female forms well-known in Argynnis, forms which he believes to be ancestral. ${ }^{29}$ It is probable that 'the recent evolution of $L$. astyanax provided this ancestral form with a model which it could approach by small and easy steps of variation.' ${ }^{30}$

The Bearing upon Theories of Mimicry of Pharm. PHilenor and Its Mimics.

Haase, who always shows an imperfect appreciation of the scope of Fritz Müller's principle, apparently regarded all the species mentioned in the preceding section as simple Batesian mimics, of philenor, neglecting the mimetic relationships between the mimics themselves. This interpretation is unconvincing, and most naturalists will agree with Scudder in his hesitation to accept the two Nymphalines, astyanax and diana (female), as simple mimics of philenor. The Müllerian hypothesis at once explains relationships that are mere coincidences under that of Bates.

Pharm. philenor, a probable intruder from the American tropics, produced its effect upon the three large Papilios-butterflies with a conspicuous under surface pattern, in large part reproducing that of the upper surface, butterflies belonging to a section that provides models for extensive Mimicry in the Oriental Region. They may be regarded as Müllerian mimics of the primary Pharmacophagus model, exhibiting a certain amount of Secondary Mimicry of one another.

The four above-named Papilionidae, but especially the three mimics acting as secondary models, then proudced an effect upon

${ }^{29}$ Trans. Ent. Soc. Lond. (1890), 89-129.

${ }^{30}$ Ibid., (1908), 475. 
L. arthemis - that same conspicuous, specially defended element in the North American butterfly fauna which was influenced in an entirely different direction by the Danaine invaders. The result of the former influence is seen in L. astyanax, a secondary mimic of the three Papilio mimics of philenor.

One of the most interesting elements in this complex mimetic system is the final appearance of a tertiary mimic of astyanax, viz., the female of Argynnis diana. This was recognized by Scudder, although, not fully appreciating the Müllerian hypothesis, he was much puzzled by the fact..$^{31}$

The under surface of the female diana is inconspicuous, and, considering also the restricted range and relative rarity of the species, it is probable that this member of the assemblage of species convergent round philenor is a Batesian mimic. But its resemblance to astyanax supports the conclusion that this latter and the sister-species archippus (and its forms) are Müllerian mimics and the parent arthemis a specially protected species. The resemblance of astyanax to the three species of the section Papilio, as well as the secondary resemblances between the three, similarly supports the conclusion that these mimics are Müllerian.

I have not hitherto called attention to the paramount need for experimental research and field observations directed to test for the presence of distasteful qualities and to estimate their effect upon enemies of the most varied kinds. It is of the utmost importance that such investigations should be undertaken on the largest possible scale. In the meantime the Müllerian Hypothesis appears to explain a series of remarkable relationships which remain coincidences under any other hypothesis.

\section{The Resemblances Between Limenitis (Adelpha) Cali- Fornica (Butl.) and Limenitis (Najas) LorQuini (BoIsD.)}

The examples of Mimicry which we have been considering hitherto are, with the exception of the widespread L. archippus, characteristic of the eastern side of North America. The present instance, the last of the examples known in this portion of the northern land-belt, is found on the Pacific coast. The resemblances are somewhat crude but of quite remarkable interest.

Limenitis californica, because of its pattern and colouring, is often placed in Adelpha, a large genus with over seventy species

${ }^{31} 1$. c. 718,1802 ; see, however, 266, where Scudder suggests that astyanax may possibly be specially protected. 
all confined to tropical America. Adelpha is separated from the closely allied northern genus Limenitis by the hairiness of the eyes in front. Californica is by this character as well as its more northern range associated with the heterogeneous assemblage "Limenitis," which so much requires a thorough revision. In adopting this view I accept the position assigned to the species by Scudder in $1875 .^{32}$

Closely allied to californica, of Oregon, California, and Nevada, is L. bredowi (Hübn.) of Arizona, Mexico, and Guatemala. A much needed investigation is the determination whether these two forms meet, and interbreed along the line of contact.

The southern species or sub-species bredowi, is associated in Mexico and Guatemala with many true species of Adelpha of which no less than thirty-one extend into Central America. To these it, and to a less extent the northern californica, bear much likeness, especially to A. dyonysa (Hew.), massilia (Feld), lerna (Hew.), and fessonia (Hew.). This likeness is probably a mimetic resemblance which extends beyond the range of the models into Arizona, and, with diminished effect, still further north into the allied sub-species. Although the details of the resemblance leave little doubt that this interpretation is correct for the southern bredowi, it is possible that californica represents an ancestral form connecting the Adelphas with Limenitis, a form left isolated and comparatively unchanged in the north, ${ }^{33}$ while its southern allies have been modified by the presence of the dominant Adelphas. At any rate in one feature neither sub-species appear to be mimetic, viz., in the yellowish tint of the conspicuous band crossing both wings; for in all the Central American Adelphas at all resembling them, this marking is pure white or bluish-white. We cannot hope to determine how far the pattern of californica is ancestral until the structural relationships and the early stages of Limenitis in the widest sense and Adelpha have been most minutely investigated.

Limenitis lorquini, occurring with L. californica in Nevada, California, and Oregon, also extends far north of this species into British Columbia and Vancouver Island. Among all the North American species of Limenitis it is the one which comes nearest to the Old World forms, as Scudder recognized when he included it with the European L. populi in the genus Najas, separating all

${ }^{32}$ Bull. Buffalo Soc. N. Sc. (Feb., 1875), 233.

${ }^{33}$ See, however, p. $234-5$. 
the other American forms of Limenitis except californica as Basilarchia. Even such fleeting characters as the markings show the Old World affinities of lorquini in the strong development of the pale spot in the fore wing cell and the position and form of the pale band crossing both wings. It is to be noted furthermore that its distribution, and especially its extension northward, along the Pacific coast, bring lorquini into closest proximity to the Old World species.

In certain important respects the upper surface pattern of L. lorquini is certainly mimetic of californica:-

The conspicuous fulvous apical area of the fore wing; the yellowish tint of the band crossing both wings, and, although here the interpretation is less certain, the fulvous marking at the anal angle of the hind wing.

I. In the first and most important of these points of superficial resemblance there is, so far as my experience goes, a much greater average development of the fulvous patch in specimens of lorquini which enter the range of califormica in Oregon and California than in those which come from Canada, entirely beyond the range of the model.

The close relationship between californica and lorquini may incline naturalists to look on their resemblance as due to affinity and not to Mimicry. "It is commonly forgotten that Mimicry, being independent of affinity, occurs between forms of all degrees of relationship, the closest as well as the most remote;" ${ }_{34}$ although of course the latter are easy to interpret, while the former may be excessively difficult. In this case, however, there is neither doubt nor difficulty, for not only is there the geographical coincidence between the model and the average increase of the marking in the mimic, but the fulvous apical marking of lorquini - of a somewhat richer, deeper shade than the tawny patch of califormica - is due to the inward growth of a marginal marking, while that of the model occupies a clearly defined sub-marginal and sub-apical position. The resemblance is, in fact, produced by markings which are essentially different; yet in some of the southern examples of lorquini in which the markings extend inward to the greatest distance the superficial resemblance is very considerable.

The above stated conclusion that the chief mimetic element of lorquini is on the average subject to considerable strengthening in the southern part of its range, is founded on an examination

${ }^{34}$ Trans. Ent. Soc. Lond. (1908), 482. 
of the few dozen specimens I have been able to study in English collections, and especially the Godman-Salvin material in the British Museum. I now trust that the subject may be taken up by American naturalists and many hundreds of specimens compared from all parts of the north and south range of the species.

2. In the second point also, the yellowish tint of the principal band, the resemblance is certainly mimetic and not due to affinity; for lorquini, ancestral in certain other features, has here lost the original whiteness of this marking, preserved not only in the Old World but in Limenitis arthemis and L. weidermeyeri (Edw.) of the New. An excessively slight deepening of the yellow tint could be made out in southern individuals from the area occupied by the model. In order to detect the difference, a long series of northern specimens should be placed beside a similar series from the south and the two compared in a strong light. But far larger numbers than I have seen ought to be examined from this point of view, and, if it were possible to make it, the comparison of perfectly fresh specimens would be most desirable.

3. The fulvous marking at the anal angle of the hind wing is excessively variable and often absent from specimens in all parts of the range. The comparison of a very large amount of material is necessary before we can reach any safe conclusions as to the existence of mimetic resemblance in this feature, and the same is true of the extremely variable under surface of lorquini, in which the development of the inner row of sub-marginal bluish lunules may be mimetic of californica. This feature was generally suppressed in the Vancouver Island specimens I have seen.

We now come to the consideration of certain differences between L. californica and its southern form bredowi which promote a likeness to lorquini. If these are not mere coincidences, we can hardly escape the conclusion that there is Reciprocal Mimicry (Diaposematism) between californica and bredowi.

I. The wings of both sexes of californica are more rounded than those of the males of bredowi, in this respect resembling both sexes of lorquini. The fact that the southern females have rounded wings may indicate that this character is ancestral in both sexes, the males alone having been modified in Mimicry of Adelpha. But it is a probable hypothesis that the presence of lorquini has prevented this mimetic feature from passing northward into the males of californica. It does pass far beyond Adelpha in the northernmost part of the range of bredowi in Arizona. 
2. The fulvous marking at the anal angle of the hind wing which forms so characteristic a feature of bredowi, is greatly reduced in californica, approximating to lorquini, which in this respect may be advancing to meet its model (see p. 233.)

3. The following points concern the band crossing the forewing. Owing to the small size of the last spot in californica and the different direction of the spot next to it, the junction between the bands of fore and hind wing forms a step-like break in californica, whereas in bredowi the bands tend to be continuous, approximating more closely to the single smooth streak crossing both wings in the Adelphas. In lorquini this step-like break and want of continuity in direction is even more pronounced. Again, the fore wing band of lorquini - one of its ancestral featuresforms with the adjacent hind wing spot, a drawn-out zigzag like a flattened-down W. By a modification in the position and direction of the spots of californica as compared with bredowi, it also gains the appearance of a very flattened $W$, although a far less regular one than that of lorquimi. The resemblance is only superficial; for corresponding spots do not occupy the upper angle of the $\mathrm{W}$ in the two species. But the attainment of a likeness by means that are different from those employed in another species supports the interpretation of the resemblance as mimetic.

Whatever be the true interpretation of the resemblances above described, it is of the utmost importance and interest to study the relative numbers of californica and lorquimi at as many different points as possible in their common range, to observe how far they fly together and present the same appearance on the wing and at rest from a little distance, and to test their relative palatability on a variety of insect-eating animals found in the same area.

The following general considerations support the conclusion that californica is not an ancient element in the Pacific fauna of North America, but a comparatively recent intruder from the south - an intruder that has modified the indigenous inhabitant lorquini and has been also reciprocally modified thereby.

Limenitis in the broad sense is part of the ancient northern butterfly fauna of North America. It has here split up into several well-marked species characteristic of the area. It is highly susceptible to mimetic influence far more so than any other North American group - and contributes the majority of the 
examples of Mimicry from this part of the world. L. archippus has been shown to be the result of a recent invasion,- - its southern and eastern forms to be still newer products of the changes in archippus itself.

The sensitiveness of the group is shown by the fact that, in spite of this recent origin, all except astyanax are most beautiful and striking mimics; and even astyanax is a better mimic than lorquini. The fact that lorquini, the member of so sensitive a group, is an undoubted mimic, but a very poor mimic, supports the conclusion that the association with its model has endured for but a brief period, a conclusion also supported by the diminution of the resemblance outside the range of californica.

If the relationships which I have found to exist in the available material - in quantity very insufficient for such minute comparisons - if these are confirmed by extensive investigations in America, it will follow that the resemblances between $L$. californica and L. lorquini will be one of the most interesting and instructive examples of Mimicry in the world. Its value will lie in the early stage reached by the resemblance, together with the diminution of the likeness in califormica to the south and, especial$1 \mathrm{y}$, in lorquini to the north. There is no reasonable doubt that lorquini forms a single Syngamic community along the Pacific Coast of North America, and we should therefore witness, first, the marked strengthening of characters in an area of selection; secondly, their transmission with diminished effect into other areas.

If what I have observed be the phenomena presented by the growth, at an early stage, of a mimetic likeness in lorquini, then that growth is "continuous" and transitional to the last and finest degree.

It is perhaps appropriate to state in a few lines how we may imagine that the selection of minute characteristics such as the presence or the position of a single spot may be made. We ourselves may observe that one individual butterfly is a better mimic than another. We may then analyse the pattern, as I have attempted to do in this address, and realize that the improvement is due to differences in one or more relatively minute elements. Recognizing the cause of the change, we are perhaps prone erroneously to suppose that enemies recognize it also and that selection has been brought to bear directly and consciously upon it. Such a view is almost certainly wrong. The only pro- 
bable hypothesis is that sharpsighted enemies, without analysing the markings, recognize differences in degrees of likeness, and that the selective pressure exercised by them is influenced by the recognition.

A great deal of attention is rightly directed at the present day to the value of experiment, and indeed it is impossible to over-estimate its importance. But while human performance is of the deepest interest for the solution of mysteries innumerable, of more profound significance still, for the comprehension of the method of evolution, is the vast performance of Nature herself. ${ }^{35}$ Because of the bright promise it holds for the understanding of Nature's experiments, I have brought before you the subject of Mimicry in North American Butterflies.

In the introductory words I spoke of the relationship of my subject to the teachings of Darwin, and now I am anxious to connect this address by a closer link to the personality of the illustrious naturalist. With the kind consent of Mr. Francis Darwin, I am able to achieve this object by printing, for the first time, a letter, recently discovered in the archives of the Hope Department of Oxford, written by Darwin to the Founder in I837. It is concerned with the insect material collected on the Beagle and is of peculiar interest because so few of Darwin's letters of this early date have been preserved. The letter clearly exhibits the keen interest which Darwin took in the working out of his collections, and the free and generous use he made of his material. A number of Diptera captured by him in Australia and Tasmania - evidently gifts to Mr. Hope - exist in the Hope Department, and are still in excellent condition. It is probable that species of other groups collected by him are also present.

\section{DeAR Hope}

I called yesterday on you and left a tin box with a few Hobart Town beetles, which I had neglected to put with the others. Is not there not [sic] a Chrysomela among them, very like the English species which feeds on the Broom.-I have spoken to Waterhouse about the Australian insects; you can have them when you like.-The collections in the pill boxes come from Sydney, Hobart town, and King George's Sound.-Do you want all orders for your work? Some are already I believe in the hands of Mr. Walker, and you know Waterhouse has described some minute Coleoptera in the papers read to the Entomo208.

${ }^{35}$ See Carl H. Eigenmann in Fifty Years of Darwinism, New York (1909), 
logical Soc: To these descriptions of course you will refer.-You will be glad to find that many of the minute Coleoptera from Sydney are mounted on cards.-Will you send me as soon as you conveniently can, one of my boxes, as I am in want of them to transplant some more insects.-Perhaps you had better return the Carabi, as they came from several localities I am afraid of some mistake. We must put out specimens for the Entomolog: Soc.: and your Cabinet. May I state in a note on your authority that a third or a half of the insects which you already have of mine from Sydney and Hobart town are undescribed.-It is a striking fact, if such is the case, for it shows how imperfectly known the insects are, even in the close neighborhood of the two Australian Capitals.

Floreat Entomologia

Wednesday.

Yours most truly,

Chas. DARWIN. ${ }^{36}$

The last words of Darwin's letter are surely a most fitting conclusion to this Anniversary Address, and I conclude by quoting his humorous repetition of them probably twenty years later.

“" 'Floreat Entomologia'!- to which toast at Cambridge I have drunk many a glass of wine. So again, "Floreat Entomologia.' N. B. I have not now been drinking any glasses full of wine. ${ }^{37}$

\section{CONCLUSIONS.}

It will probably be convenient to sum up rather fully the chief conclusions contained in the foregoing address.

I. The study of Mimicry possesses special advantages for an understanding of the history and causes of evolution.

2. North America is the most suitable area in the world in which to begin the study of Mimicry.

3. The great American Danaine butterflies, formerly included in the genera Anosia and Tasitia, are a foreign element in the New World fauna. They bear the closest affinity to a large group of indigenous Old World Danainae, and should be fused with the nearest of these (Limnas, and Salaiura) into a single genus, Danaida.

${ }^{36}$ The letter is addressed: "The Revd. F. W. Hope, 56, Upper Seymour Street." At the head Mr. Hope had written "D," and the date "1837." The red-stamped post-mark gives the date "Ju. 22, 1837." Darwin's own address (36, Great Marlborough Street) does not appear. At the date of the letter the Entomological Society of London possessed a large collection of insects, long since dispersed. Darwin knew Mr. Hope before the Voyage, and speaks in letters to W. D. Fox $(1829-30)$ of his splendid collection and of his generosity with specimens. He also went for an entomological trip in North Wales with Hope (June, 1829), unfortunately broken short for Darwin by ill health. See Life and Lettêrs, i. 174, 175, 178, 181. G. R. Waterhouse and Francis Walker, referred to in the letter, were both on the staff of the British Museum.

${ }^{37}$ To Sir John Lubbock (Lord Avebury), some date before 1857. - Life and Letters ii. 141 . 
4. The Old World origin of Danaida is also proved by the extent and variety of its mimetic relationships; while the path of its invasion of the New World and of South by way of North America, may be traced by foot-prints, as it were, of mimetic effect.

5. That Danaida plexippus is the older invader is equally shown by the depth of the impression it has made and the amount of change it has itself undergone in the New World.

6. Danaida berenice and its form strigosa show comparatively slight changes in the New World, and, as regards mimetic influence, have but deepened the foot-prints left by plexippus.

7. Limenitis arthemis, the indigenous ancestor of the mimic of plexippus, persits with little or no change; and it is possible to show how far the very different markings of the mimetic daughter species, L. archippus, have been carved out of those of the parent.

8. The recent date of this great superficial transformation is proved by the close resemblances between the larval and pupal stages of parent and offspring. L. archippus also probably occasionally interbreeds with the mimetic $L$. astyanax - a still younger descendant of the same parent.

9. L. archippus probably arose on the southern borders of arthemis, but afterwards ranged northwards over the area of the parent species.

Io. The southern astyanax, meeting the northern arthemis along a narrow belt, is probably repeating the earlier history of archippus.

II. The forms of sub-species of archippus - floridensis in Florida and hulsti in Arizona-have arisen from the earlier mimic of $D$. plexippus as a result of the predominance in these localities respectively, of Danaida berenice and its form strigosa.

I2. Details of the older Mimicry persist in floridensis (and perhaps in hulsti), somewhat detracting from the newer resemblance.

I3. Certain features in the mimetic likeness newly attained in Florida and Arizona are probably due to the recall or the reemphasis of elements in the pattern of arthemis which had been greatly reduced in archippus.

I 4. The fact that the invading Danaidas have only influenced among the whole indigenous butterfly fauna, the dominant conspicuous Nymphaline genus Limenitis, supports a Müllerian as opposed to a Batesian interpretation of the phenomena. 
I 5. The fact that the ancestral pattern of a species indigenous in the temperate zone of the New World should be wholly transformed by a recent invader from the Old World tropicsthe invader meanwhile retaining its original characteristic pattern, is demonstrative of the inadequacy of the theory which refers these likenesses to the influence of soil, climate, etc.

I6. The poison-eating "Aristolochia swallow-tail" Pharmacophagus (Papilio) philenor belongs structurally to the American division of this tropical section, and is probably an intruder into North America from the south.

I 7. Just as tropical species of Pharmacophagus are mimicked, especially by other sections of swallow-tails, so the invading philenor is mimicked by three species of the section "Papilio."

I8. Of these three-Papilio troilus, mimetic in both sexes, is probably the oldest; $P$. asterius, mimetic in female and on under surface of male, the next; and $P$. glancus, mimetic in one out of the two forms of female (the mimetic form becoming more numerous in the south of the range), the youngest.

I9. The ancestors of these mimics persist with little or no change-in the two last-named species, the non-mimetic sex or form, in the first-named the allied palamedes. By their aid we can reconstruct the history of the transformation.

20. In asterius and glancus partially melanic forms of the female probably supplied a tinted background on which the new and mimetic picture was gradually built up by the modification of elements in the original non-mimetic pattern.

$2 \mathrm{I}$. The close resemblance between the three mimicking species cannot be entirely explained by their convergence upon a single model, but seems to imply the existence of Secondary Mimicry between them.

22. Limenitis astyanax has arisen as a very recent modification of arthemis in Mimicry of philenor, and especially in Secondary Mimicry of the three Papilio mimics.

23. The female of Argynnis (Semnopsyche) diana has arisen as a tertiary mimic, on the upper surface, of $L$. astyanax. Its under surface, inconspicuous with that of the male when contracted, suggests that the species is palatable as compared with the rest of this combination and that its Mimicry is Batesian.

24. The dark ground and pale markings of the female diana are probably analogous with those of other dark female forms in Argynnidae, while the blue colouring is an additional feature of purely mimetic significance. 
25. The arrangement of the North American butterflies which converge on Pharm. philenor, in concentric rings each mimetic of that lying within it, strongly supports a Müllerian interpretation of all except the species (diana) in the outermost layer.

26. Limenitis (Adelpha) californica of the Pacific coast is probably a Limenitis mimic of the South American genus Adelpha, to which its southern sub-species bredowi bears a stronger resemblance.

27. Limenitis (Najas) lorquini, in some respects the most ancestral of the North American species of the group, is in other respects a mimic of $L$. californica.

28. Certain features in which lorquini superficially resembles californica are on the average more strongly developed in the area where the two species overlap, while they diminish when lorquini passes northward of this area.

29. The differences between bredowi, ranging entirely south of lorquini, and californica are such as to promote a superficial resemblance between the latter and lorquini, supporting the hypothesis that the resemblances between them have been caused by reciprocal approach (Diaposematism).

30. The differences which distinguish bredowi from californica are such as to promote a resemblance to the tropical American genus Adelpha. They are retained by bredowi in Arizona, north of the range of any true Adelpha. ${ }^{38}$

3I. The detailed study of these resemblances on the Pacific Coast of North America leads to the conclusion that the Mimicry is in an incipient stage and that it has been reached and is probably still advancing by minute increments, - that the evolution is "continuous" to the last degree.

32. In addition to their bearing upon the problems of Mimicry, the examples considered in the address afford some of the very best material for testing the operation of Mendel's Law under natural conditions.

I wish again to caution my readers that the above conclusions have been drawn from the careful study of a limited number of examples. Although insufficient in quantity, the English material is as a whole excellent in quality. Thus, many of the Pacific

${ }^{38}$ In the southernmost part of the range of bredowi, in Guatemala, the resemblance to Adelpha was very slightly augmented in the only two specimens from this locality I have had the opportunity of studying (Trans. Ent. Soc. Lond., $1908,485)$. 
coast specimens were captured by Lord Walsingham, Dr. F. D. Godman, and Mr. H. J. Elwes, and the geographical data are of course as full and precise as we should expect or wish.

I trust that my brother naturalists in America will make a determined attack on the fascinating problems offered by the phenomena of Mimicry in the North American butterfly fauna. In this favoured part of the world the problems have been seen to be sharp and clear as compared with the almost infinite complexity of the tropics. If my assistance or advice be of any value it is always at the service of those who desire to undertake such investigations.

It has been abundantly shown in the course of the address, that immense numbers of specimens are required from the most varied localities; and it is likely that difficulties may be presented by the necessary manipulation, labelling, convenient arrangement and permanent preservation for the study of future as well as living naturalists, of so large a mass of material. I shall, however, be most pleased to undertake this part of the investigations as regards all specimens accompanied by adequate data of space and time. 'Such material, preserved in the Hope Department, may be readily compared with the ever-increasing mass of examples illustrating the same principles in other parts of the world. If the indications observed in a small series are still found to hold in a large one, the growth of such a feature as the orangebrown apex of the fore wing in Limenitis lorquini would be demonstrated by a glance at its average condition in specimens from the different localities as we pass from north to south. Furthermore, we might reasonably hope that a similar series collected after an interval not greatly prolonged would exhibit differences in average composition - the actual measurable evidence of the evolution of a character in a species in the natural state. Even though such evidence be left for our successors to witness, it still remains our duty to provide them with the standard by which alone they will be able to detect and measure it. But I am hopeful of more than this, and think it by no means unlikely that a part of the reward may be reaped by a single generation of workers.

An excellent example of work done in a single locality, work which now requires to be extended to many species in many localities, is afforded by the data obtained by Mr. J. H. Cook, and summarized in the following note. 
Note.-The capture of males of $L$. archippus in which the black stripe was wanting from the upper surface of the hind wing, and of transitional forms of both sexes at Albany, N. Y., by John H. Cook.

Mr. Cook first met with the stripeless form in June, 1898, near Hudson, N. Y. A second specimen was captured near his home in Albany in 1901 and a third in the same field in the following year. This latter was a beautiful specimen apparently only just emerged from the pupa. Mr. Cook's attention was now thoroughly aroused and he collected assiduously at Albany during three seasons, always working on the best ground to the west of the city, and taking over 90 specimens with the stripe wholly or nearly suppressed. The following conclusions were reached:-(1) All the stripeless archippus captured were males; (2) The females shared the tendency but never reached the extreme found in the other sex; (3) Most of the individuals taken showed some weakening of the stripe, varying from a slight break (most commonly between veins III and $\mathrm{V}_{2}$ and between $\mathrm{V}_{3}$ and $\mathrm{VII}_{2}$, of the system of Comstock and Needham) to complete suppression on the upper surface; (4) At Albany individuals with a broken stripe outnumbered those with an entire stripe in the proportion of about 18 to 1 , while stripeless specimens were taken in the average proportion of 1 to 14. Mr. Cook also collected data from other localities and endeavored to interest correspondents in the problem. Including the Albany material he secured records of about 1600 specimens and was able to reach the conclusion that in New England and the Middle States broken-striped individuals are not uncommon though generally outnumbered by those with a continuous stripe. He did not meet with any record of a perfectly stripeless form except for his own observations and the two specimens to which the name pseudodorippus has been given. Strecker's type of this form exists in Dr. W. J. Holland's collection (Butterfly Book, New York [1899], 185). These two psendodorippus were also taken in the Eastern States (the Catskill Mountains, and in Massachusetts), but Mr. Cook, who has seen one and received from Dr. Holland an account of the other, believes that the disappearance of the stripe is here part of a general blurring of the colour-scheme in which some elements are obliterated and there is a tendency towards the invasion of one colour-area by another. The extreme varieties captured by $\mathrm{Mr}$. Cook himself, did not, on the other hand, differ at all from the normal archippus except in the absence of the black stripe from the upper surface of the hind wings. To this stripeless variety $\mathrm{Mr}$. Cook and $\mathrm{Mr}$. Watson have given the name lanthanis. Mr. Cook's accurate data and most of his specimens were unfortunately destroyed when the college buildings at Albany were burnt down on Jan. 6, 1906. It is much to be hoped that he may be able to continue his most interesting observations in this favourable locality, and that naturalists may be stimulated, by these reeords, now by Mr. Cook's kindness made public for the first time, to work in other North American localities. 


\section{$2 \mathrm{BHL}$ Biodiversity Heritage Library}

Poulton, Edward Bagnall. 1909. "Mimicry in the Butterflies of North America." Annals of the Entomological Society of America 2, 203-242.

https://doi.org/10.1093/aesa/2.4.203.

View This Item Online: https://www.biodiversitylibrary.org/item/38095

DOI: https://doi.org/10.1093/aesa/2.4.203

Permalink: https://www.biodiversitylibrary.org/partpdf/193507

\section{Holding Institution}

Smithsonian Libraries

\section{Sponsored by}

Smithsonian

\section{Copyright \& Reuse}

Copyright Status: NOT_IN_COPYRIGHT

This document was created from content at the Biodiversity Heritage Library, the world's largest open access digital library for biodiversity literature and archives. Visit BHL at https://www.biodiversitylibrary.org. 